\title{
Defect Engineering in Graphene-Confined Single-Atom Iron Catalysts for Room-Temperature Methane Conversion
}

\author{
Xin Tan*, Hassan A. Tahini, Sean C. Smith*
}

\begin{abstract}
Integrated Materials Design Laboratory, Department of Applied Mathematics, Research School of Physics, The Australian National University, Canberra, ACT 2601, Australia.
\end{abstract}

*Corresponding author: Xin.Tan@anu.edu.au, Sean.Smith@anu.edu.au 
(a)
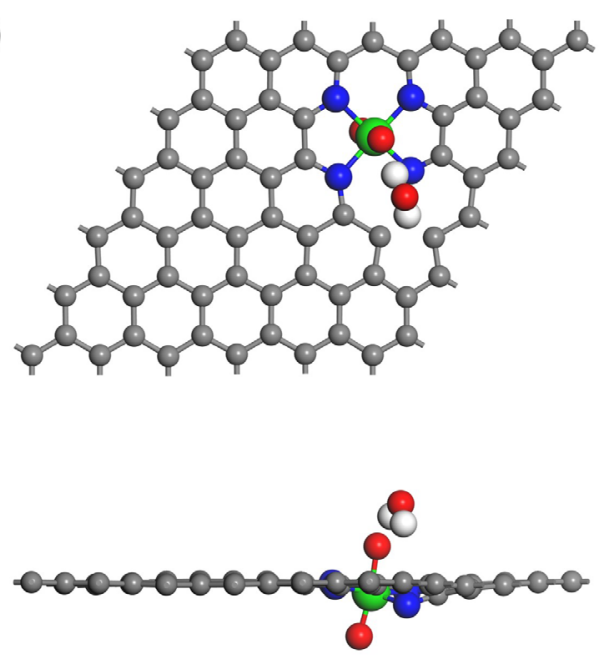

$-0.55 \mathrm{eV}$ (b)
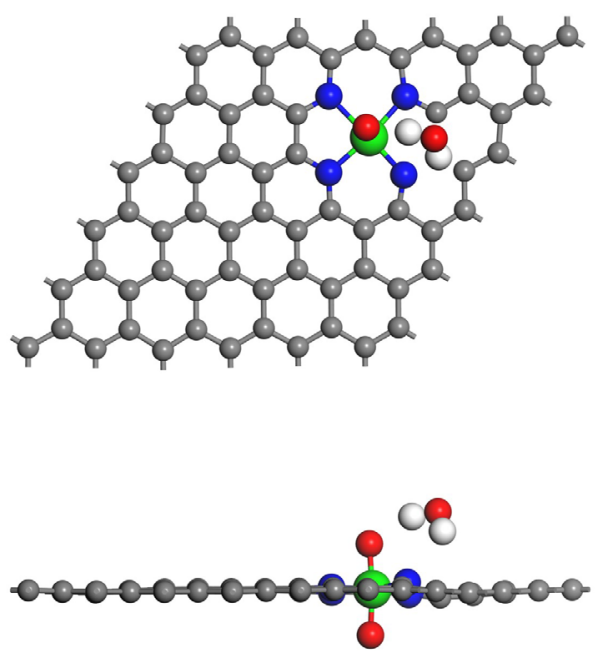

$-0.49 \mathrm{eV}$

Figure S1. The optimized geometric structures of $\mathrm{H}_{2} \mathrm{O}$ adsorption on (a) $\mathrm{FeN}_{4}-\mathrm{V}_{6 \mathrm{r}}$ and (b) $\mathrm{FeN}_{4}-\mathrm{V}_{5 \mathrm{r}}$. The corresponding adsorption energies of $\mathrm{H}_{2} \mathrm{O}$ are listed below. 


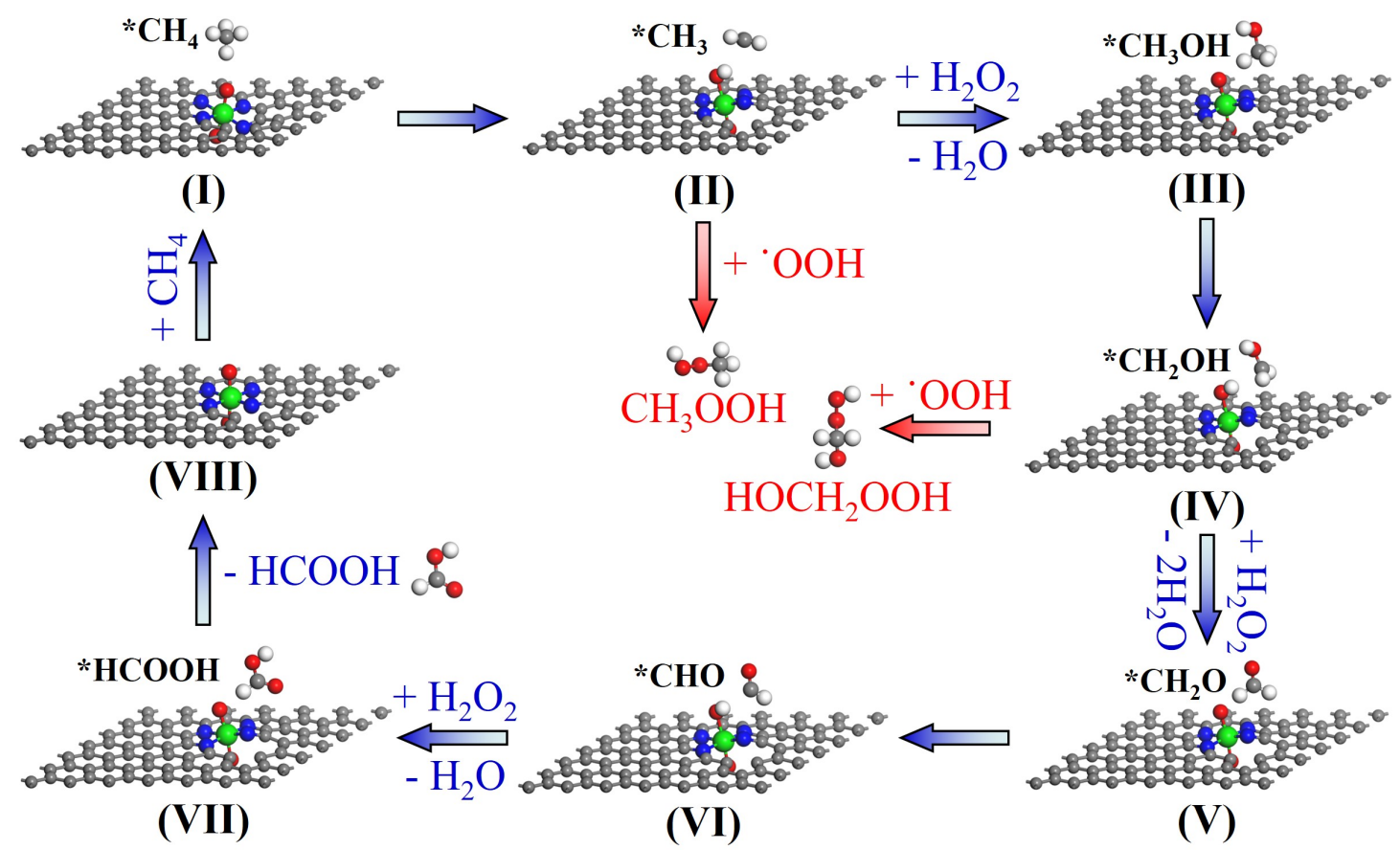

Figure S2. The optimized geometric structures of methane conversion to $\mathrm{C} 1$ oxygenates on $\mathrm{FeN}_{4}-\mathrm{V}_{6}$ along a radical pathway. 

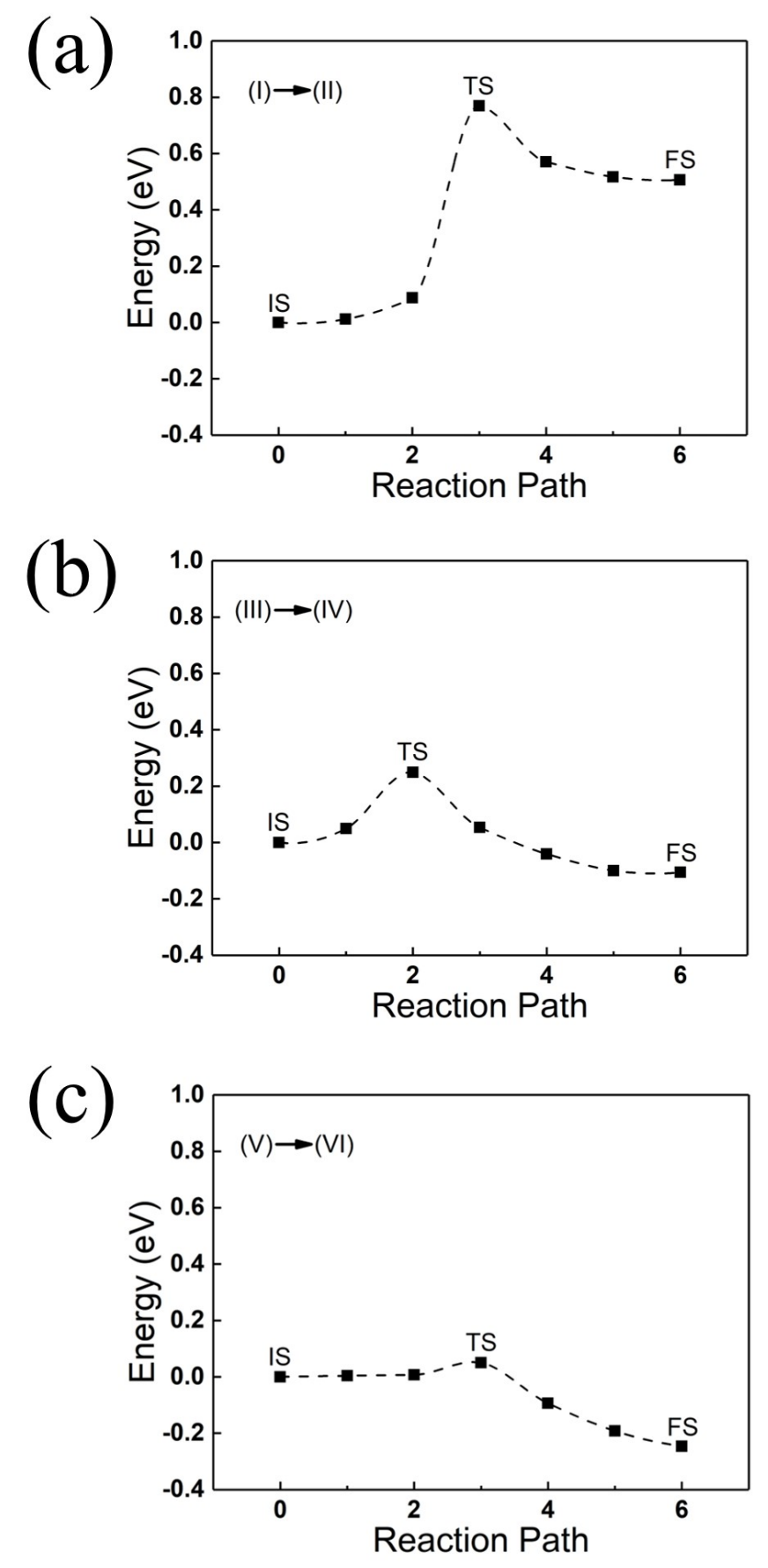

Figure S3. The minimum energy pathways from NEB calculations for (a) $\mathrm{I} \rightarrow \mathrm{II}$, (b) $\mathrm{III} \rightarrow \mathrm{IV}$, and (c) $\mathrm{V} \rightarrow \mathrm{VI}$ on perfect oxidized FeN4. Here IS, TS, and FS denote the initial state, transition state, and final state, respectively. 

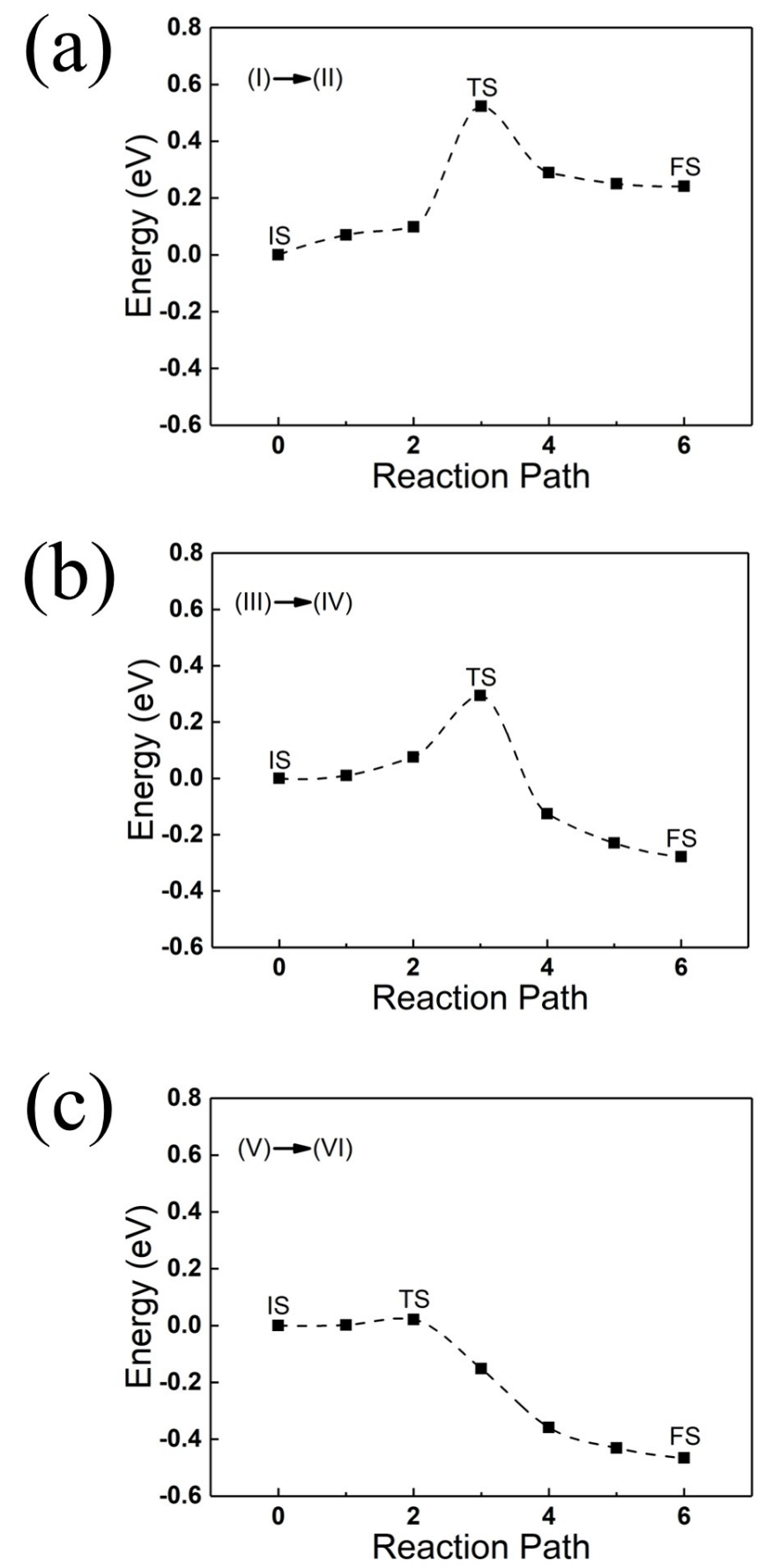

Figure S4. The minimum energy paths from NEB calculations for (a) $\mathrm{I} \rightarrow \mathrm{II}$, (b) $\mathrm{III} \rightarrow \mathrm{IV}$, and (c) $\mathrm{V} \rightarrow \mathrm{VI}$ on oxidized $\mathrm{FeN}_{4}-\mathrm{V}_{6 r}$. Here IS, TS, and FS denote the initial state, transition state, and final state, respectively. 

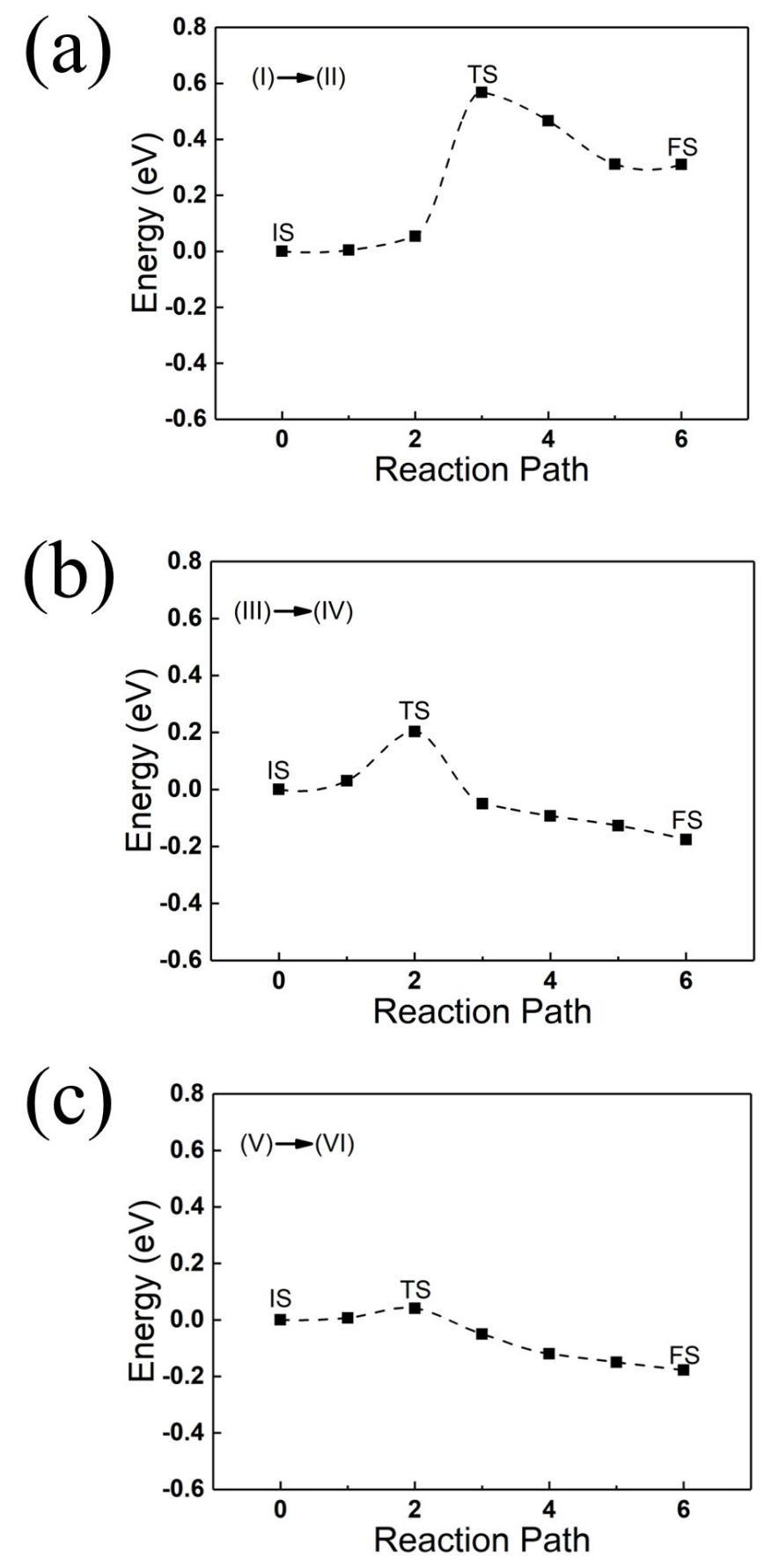

Figure S5. The minimum energy pathways from NEB calculations for (a) I $\rightarrow$ II, (b) $\mathrm{III} \rightarrow \mathrm{IV}$, and (c) $\mathrm{V} \rightarrow \mathrm{VI}$ on oxidized $\mathrm{FeN}_{4}-\mathrm{V}_{5 \mathrm{r}}$. Here IS, TS, and FS denote the initial state, transition state, and final state, respectively. 

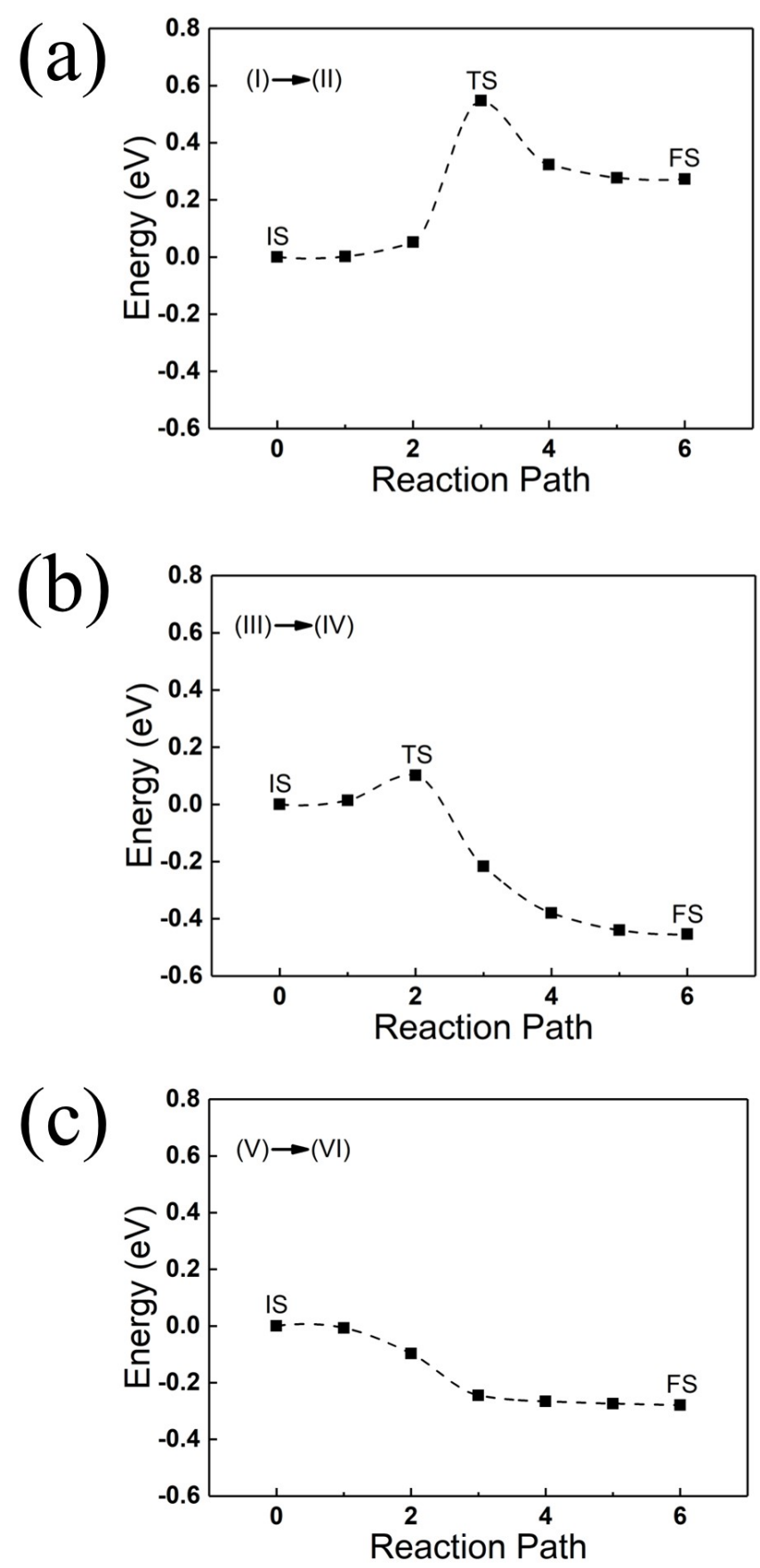

Figure S6. The minimum energy pathways from NEB calculations for (a) I $\rightarrow$ II, (b) $\mathrm{III} \rightarrow \mathrm{IV}$, and (c) $\mathrm{V} \rightarrow \mathrm{VI}$ on oxidized $\mathrm{P}-\mathrm{O} / \mathrm{FeN}_{4}$. Here IS, TS, and FS denote the initial state, transition state, and final state, respectively. 
(a)

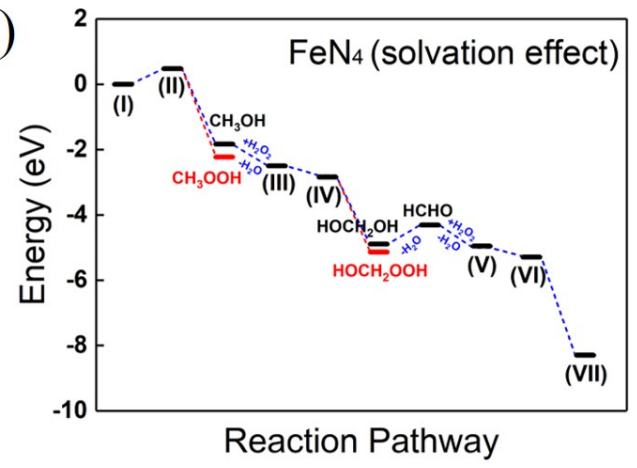

(b)

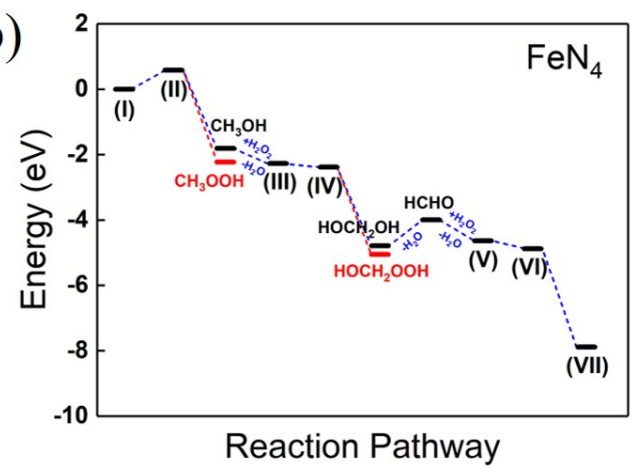

Figure S7. The complete free energy profiles of methane conversion to $\mathrm{C} 1$ oxygenates on perfect oxidized $\mathrm{FeN}_{4}$ (a) with solvent effect and (b) without solvent effect. Note that the solvent effect is considered with the implicit solvent model implemented in VASPsol.

The solvation correction or the energy difference between the free energy with and without solvent effect were found to be relatively small compared to the differences in the free energies among the key intermediates, therefore we did not include them in the calculations of the free energy profiles. 


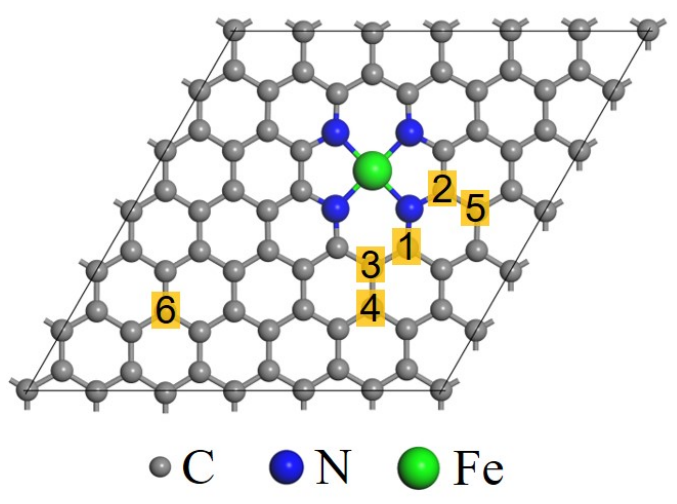

\begin{tabular}{|c|c|c|c|}
\hline \multirow{2}{*}{ Doping Site } & \multicolumn{3}{|c|}{ Relative energy (eV) } \\
\cline { 2 - 4 } & B doping & S doping & P doping \\
\hline 1 & 0 & 0 & 0 \\
\hline 2 & 0.83 & 0.18 & 0.08 \\
\hline 3 & 0.83 & 0.59 & 0.34 \\
\hline 4 & 0.91 & 0.35 & 0.74 \\
\hline 5 & 1.35 & 0.62 & 1.05 \\
\hline 6 & 1.28 & 0.56 & 0.86 \\
\hline
\end{tabular}

Figure S8. Atomistic structure of perfect $\mathrm{FeN}_{4}$ model used in our calculations. The numbers denote the possible substitutional doping sites of heteroatoms (B, P or S), and the corresponding relative formation energies of the dopants are listed in the table on the right. 
(a)
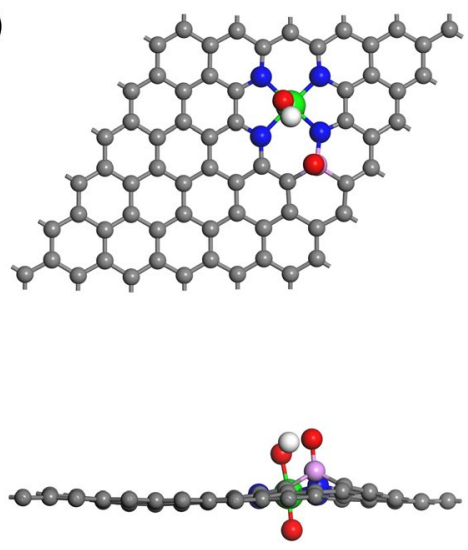

$0 \mathrm{eV}$ (b)
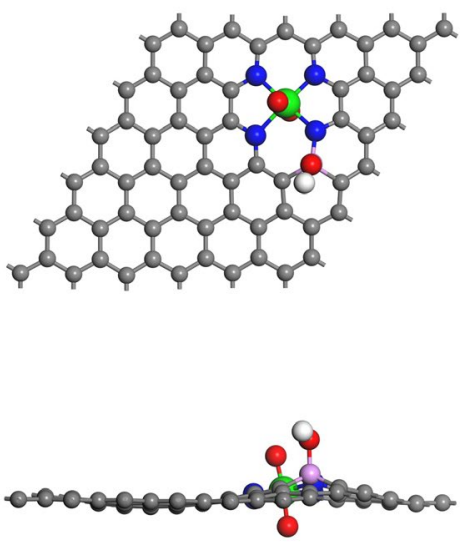

$1.78 \mathrm{eV}$

Figure S9. The optimized geometric structures of $\mathrm{H}$ adsorption at (a) $\mathrm{Fe}-\mathrm{O}$ and (b) P-O sites. The corresponding relative adsorption energies of $\mathrm{H}$ are listed below, which indicate the $\mathrm{H}$ prefer to adsorb at $\mathrm{Fe}-\mathrm{O}$ site. 

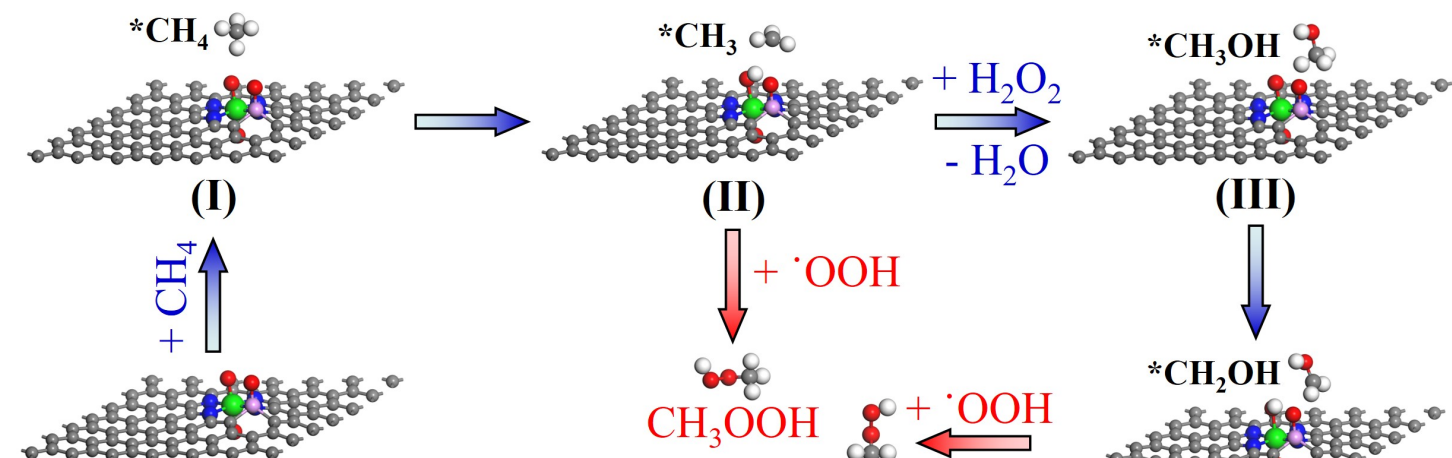

(II)

(III)

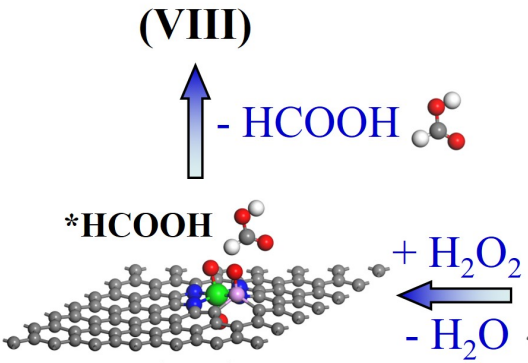

(VII)<smiles>OO[c+]1cc1</smiles><smiles>C1=CC=C1</smiles>

$\mathrm{CH}_{3} \mathrm{OOH}{ }_{80}^{\circ}+{ }^{\circ} \mathrm{OOH}$ ${ }^{*} \mathrm{CH}_{2} \mathrm{OH}{ }_{8}$

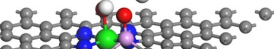
$\mathrm{HOCH}_{2} \mathrm{OOH}$

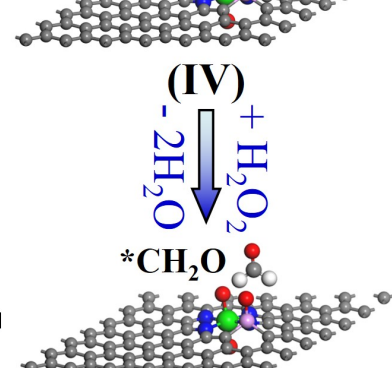

*CHO \&

(V)

Figure S10. The optimized geometric structures of methane conversion to $\mathrm{C} 1$ oxygenates on $\mathrm{P}-\mathrm{O} / \mathrm{FeN}_{4}$ along a radical pathway. 

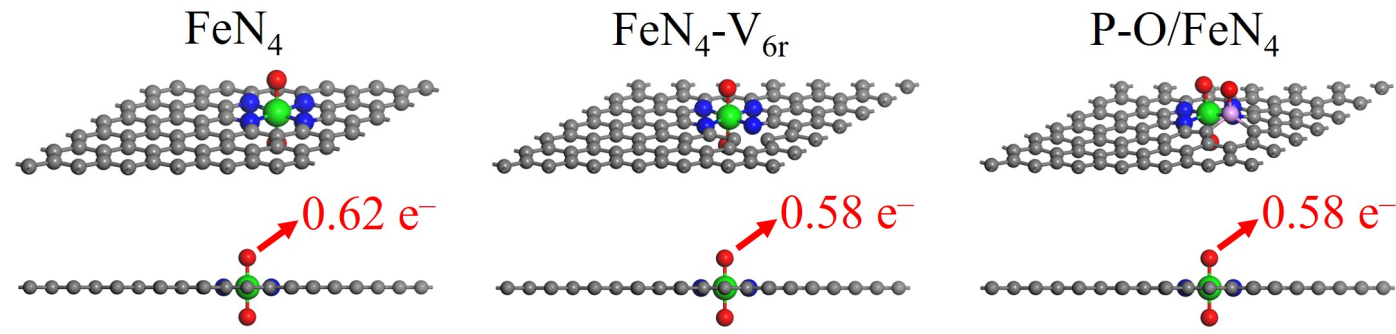

Figure S11. The calculated charge states of top $\mathrm{O}$ atom in $\mathrm{O}-\mathrm{FeN}_{4}-\mathrm{O}$ active centers on perfect oxidized $\mathrm{FeN}_{4}$, oxidized $\mathrm{FeN}_{4}-\mathrm{V}_{6 \mathrm{r}}$, and oxidized $\mathrm{P}-\mathrm{O} / \mathrm{FeN}_{4}$ based on Bader analysis. 